\title{
HOLAKRACJA JAKO NOWA KONCEPCJA ELASTYCZNEJ ORGANIZACJI - PRÓBA OCENY
}

DOI: $10.33141 /$ po.2020.02.01

Bernard Ziębicki
Przegląd Organizacji, Nr 2(961), 2020, s. 3-10 www.przegladorganizacji.pl ๑) Towarzystwo Naukowe Organizacji i Kierownictwa (TNOiK)

\section{Wprowadzenie}

$\mathbf{K}^{\mathrm{n}}$ luczowym wyzwaniem praktyki współczesnego zarządzania staje się zapewnienie elastyczności organizacji. Tradycyjne modele zarządzania, wykorzystujące wieloszczeblowe struktury organizacyjne, stawiające na specjalizację, oparte na sformalizowanych procedurach, stają się coraz mniej skuteczne. Dynamika zmian otoczenia, związana z pojawianiem się nowych modeli biznesowych, rozwojem technologii informatycznych, automatyzacją procesów oraz wzrostem złożoności konkurowania $\mathrm{w}$ warunkach postępującej globalizacji, powoduje konieczność zmiany podejścia do zarządzania. Szczególnym wyzwaniem $\mathrm{w}$ przedstawianych warunkach jest zbudowanie zaangażowania pracowników, zapewniającego wysoką efektywność i rozwój organizacji. W konsekwencji opisywanych tendencji, w praktyce zarządzania, dokonują się zmiany, polegające na spłaszczaniu struktur organizacyjnych, orientacji procesowej, delegowaniu uprawnień, promowaniu inicjatywy i przedsiębiorczości wewnętrznej, rozwijaniu zespołowości, a także wykorzystywaniu narzędzi informatycznych, w celu automatyzacji działań oraz zwiększania efektywności komunikacji rynkowej. Zmiany te związane są również z tworzeniem nowych koncepcji zarządzania, jak: turkusowa organizacja, empowerment, zwinne zarządzanie, zespoły równoległe czy też jeszcze nieco mniej znane: model podularity, grupy spiskowców, sieci indywidulanego kontraktowania. Do grupy tej należy również koncepcja holakracji, której dotyczy artykuł. Cechą wspólną wymiennych koncepcji jest wykorzystywanie zjawiska samoorganizacji. Można uznać, że koncepcje te stanowią różne jej formy (Gulati, 2018, s. 68-70).

Celem artykułu jest przedstawienie zasad funkcjonowania oraz próba oceny holakracji, stanowiącej jedną z najnowszych koncepcji samoorganizacji. Koncepcja ta dotychczas nie była stosowana $w$ polskich przedsiębiorstwach. Z tego względu jako metodę badawczą zastosowano desk research, obejmujący analizę źródeł literaturowych, dotyczących założeń holakracji oraz case study, przedstawiających jej wdrożenia w praktyce gospodarczej. W rezultacie określono główne determinanty sukcesu oraz czynniki ryzyka, związane $\mathrm{z}$ wdrażaniem tej koncepcji. Wskazano także kierunki dalszych badań naukowych w tym obszarze. Należy również dodać, że holakracja stanowi nową koncepcję zarządzania, podejmowaną dotychczas w nielicznych pracach naukowych. Główne źródła dotyczące tej koncepcji to opracowania popularne, zamieszczane w Internecie. Nie były dotychczas prowadzone również szersze badania naukowe $\mathrm{w}$ tym obszarze (Bhandari, Colomo-Palacios, 2019, s. 140).

\section{Geneza $\mathrm{i}$ istota holakracji}

$\mathrm{H}$ olakracja (holacracy) stanowi młodą koncepcję zarządzania. Za oficjalną datę jej powstania uznaje się rok 2006, kiedy to po raz pierwszy została ona zastosowana w firmie Ternary Software w Pensylwanii (Krasulja, 2016, s. 191). Autorstwo tej koncepcji przypisuje się Brianowi Robertsonowi, właścicielowi firmy. Jest on również autorem manifestu holakracji, określającego formalne zasady funkcjonowania organizacji opartej na tej koncepcji. Obecnie B. Robertson jest właścicielem firmy konsultingowej HolacracyOne, zajmującej się wdrażaniem holakracji w biznesie.

Holakracja rozwija się bardzo dynamicznie i ma coraz więcej zwolenników. Jak się szacuje, została ona już wdrożona w kilkuset przedsiębiorstwach, a także organizacjach non-profit, na całym świecie. Rozgłos koncepcja ta uzyskała w związku z wdrożeniem jej w 2015 roku w amerykańskiej firmie Zappos, internetowym sklepie, sprzedającym buty i odzież, będącym obecnie częścią Amazonu. Zappos, z zatrudnieniem na poziomie 1500 osób, to największa firma, jaka dotychczas wdrożyła holakrację (Van de Kamp, 2014, s. 15).

Nazwa holakracja wywodzi się od filozoficznego pojęcia holarchii, wprowadzonego przez A. Koestlera, autora książki Ghost in the Machine (Koestler, 1967). Praca ta poświęcona została filozoficznym rozważaniom, dotyczącym reguł rządzących otaczającym nas światem. A. Koestler próbuje dowieść, że otaczający nas świat składa się z autonomicznych bytów (atomów, komórek), które jednocześnie stanowią elementy większych całości (np. organizmów). Byty te nazwał ogólnie holonami (z grec. holon - całość). Holony, stanowiąc elementy większych całości, funkcjonują w układzie wzajemnych zależności i relacji względem siebie oraz bytów nadrzędnych, tworząc szczególne hierarchie, określane przez A. Koestlera mianem holarchii.

Koncepcja A. Koestlera rozwinięta została przez współczesnego amerykańskiego filozofa Kena Wilbera $\mathrm{w}$ ramach teorii integralnej. Podstawowym założeniem tej teorii jest twierdzenie, że holony występują dosłownie wszędzie (Wilber, 2001). Zbudowane są z nich zarówno 
materialne, jak i niematerialne byty otaczającego nas świata. Jako przykłady K. Wilber podaje atomy, które stanowią elementy cząsteczek, te natomiast są częściami komórek, które następnie tworzą organizmy i tak dalej. Podobnie litery są częściami słów, które składają się na zdania, akapity, opowiadania. Każde $\mathrm{z}$ tych powiązań jest przykładem holarchii, czyli zagnieżdżonej hierarchii holonów o wzrastającej złożoności, gdzie każdy holon wyższego rzędu przekracza i obejmuje holony z niższego poziomu. Tworzone $\mathrm{w}$ ten sposób układy nie stanowią prostej sumy części, ale kreują nową, synergiczną wartość (Robertson, 2015, s. 39).

Istotną rolę w powstaniu i rozwoju koncepcji holakracji we współczesnym zarządzaniu przypisuje się również zwinnemu zarządzaniu. Związane jest ono przede wszystkim $\mathrm{z}$ nowatorskim podejściem $\mathrm{w}$ zakresie realizacji projektów informatycznych, stanowiącym alternatywę dla tradycyjnego, kaskadowego modelu tworzenia oprogramowania. Istota modelu kaskadowego sprowadza się do realizacji projektu w układzie następujących po sobie etapów, takich jak: określenie wymagań oprogramowania, projektowanie, tworzenie, testowanie, wdrożenie. Rozpoczęcie kolejnego etapu następuje dopiero po zakończeniu wcześniejszego. W podejściu tym zakłada się również, że użytkownicy są w stanie precyzyjnie zdefiniować oczekiwania co do przyszłego produktu (programu) oraz że środowisko biznesowe jest względnie stabilne (nie zmienia się przez czas realizacji projektu) (Cobb, 2012, s. 6). We współczesnych warunkach, ogromnej dynamiki zmian technologii informatycznych, model ten coraz częściej okazuje się być nieskuteczny. Alternatywą stało się przyrostowe podejście adaptacyjne, określane jako zwinne, którego głównymi założeniami są: elastyczność działania oraz intensywna współpraca $\mathrm{z}$ klientem $\mathrm{w}$ trakcie realizacji całego projektu. W praktyce gospodarczej coraz częściej pojawiają się opinie, że podejście to nie powinno dotyczyć realizacji tylko pojedynczych projektów, ale znajdować zastosowanie w zarządzaniu na poziomie całej organizacji, zapewniając jej wysoką elastyczność i ciągłą komunikację z klientem, co stanowi jeden z głównych celów tworzenia organizacji holakratycznych (Laloux, 2015, s. 379).

Kluczową rolę dla powstania holakracji odegrała jednak koncepcja socjokracji. Można uznać, że holakracja stanowi jej rozwinięcie i sformalizowanie. Socjokracja to koncepcja zarządzania, której autorstwo przypisywane jest Gerardowi Endenburgowi, holenderskiemu przedsiębiorcy, twórcy metody socjokratycznych kręgów organizacyjnych (ang. The Sociocratic Circle Organisation Method - SCM) (Romme, 1995, s. 213). Inspiracją dla G. Endenburga były prace Cornelisa (Keesa) Boeke, holenderskiego pedagoga-reformatora, który w latach 40. XX wieku po raz pierwszy użył określenia socjokracja dla nazwania, opracowanego przez siebie, nowego podejścia w edukacji dzieci, polegającego na włączaniu ich do współdecydowania o procesie kształcenia na równych prawach z nauczycielami. Pozwoliło to rozwinąć ich kreatywność oraz zaangażowanie, zwiększając w rezultacie skuteczność procesu edukacji (Buck, Villines, 2007, s. 191). Opracowana przez G. Endenburga metoda opiera się na czterech założeniach: podejmowanie decyzji „za zgodą”; kręgi, „podwójne łączenie” i wybory. Decyzje w socjokracji podejmowane są kolektywnie, na zasadzie zgody, nie konsensusu, czyli gdy nie ma „uzasadnionego sprzeciwu”. Konsensus wymaga akceptacji określonego rozwiązania przez wszystkich. W warunkach organizacji osiągnięcie takiego stanu jest bardzo trudne, a często wręcz niemożliwe. W procesie decyzyjnym w socjokracji dąży się do wykreowania rozwiązania, które nie będzie budziło konstruktywnych zastrzeżeń. Rozwiązanie takie uznaje się za akceptowane przez wszystkich. Drugim elementem socjokracji jest zastąpienie hierarchicznej struktury półautonomicznymi grupami, określanymi jako „kręgi”, posiadającymi odrębne cele i przejmującymi odpowiedzialność za ich realizację. Kręgi te łączą się, uwzględniając potrzeby kręgów niższego i wyższego poziomu. Co najmniej dwie osoby (red link) z niższego kręgu uczestniczą w podejmowaniu decyzji w kręgu wyższego poziomu. Zasada ta określna jest jako „podwójne łączenie”. Ostatnia zasada - wybory - związana jest $\mathrm{z}$ powierzaniem pracownikom funkcji w kręgach w drodze wyborów, poprzedzonych otwartą dyskusją (Eckstein, Buck, 2018, s. 35-38).

Przedstawione założenia socjokracji zostały wykorzystane w koncepcji holakracji opracowanej przez B. Robertsona. W holakracji, tak samo jak w socjokracji, podstawowym elementem organizacji są autonomiczne kręgi, będące odpowiednikami holonów. Najmniejsze kręgi tworzą pracownicy o różnych kompetencjach, którym zostają przypisane role. Kręgi te stanowią jednocześnie elementy większych całości - kręgów nadrzędnych (kręgów departamentów, pionów czy kręgu całej organizacji). Kręgi tworzone są zależnie od potrzeb. Część kręgów ma charakter stały, część natomiast istnieje jedynie do czasu osiągnięcia celu, jaki przyświecał ich utworzeniu. Kręgi w holakracji są autonomiczne w zakresie przypisanych im celów i zadań. Wszystkie decyzje w ramach kręgu podejmowane są kolektywnie, w trakcie regularnie odbywających się zebrań. Nie ma szefa. Pracownicy wypełniają określone role, które przypisywane są im przez zespół (uczestników kręgu), zależnie od ich indywidualnych kompetencji. Pracownik może jednocześnie wypełniać kilka ról. Tak jak w socjokracji kręgi są „podwójnie połączone”. Dwie osoby z kręgu niższego biorą udział w podejmowaniu decyzji w kręgu wyższym. Są nimi: osoba odpowiedzialna za kontrolę wyników kręgu niższego (pełniąca rolę lidera zespołu) oraz druga, wybrana przez członków kręgu (Robertson, 2015, s. 28) (rys. 1).

Funkcjonowanie organizacji holakratycznej opiera się na sformalizowanym regulaminie. Najczęściej jest on tworzony na zasadzie „ratyfikowania” konstytucji holakracji, opracowanej przez B. Robertsona. Jest ona nieustannie rozwijana przez autora.

\section{Schemat działania organizacji holakratycznej}

D odstawą zarządzania pracą kręgu są kolektywne uzgodnienia w ramach zebrań. Mają one dwojaki charakter - zebrań zarządczych oraz operacyjnych. Pierwsze z nich dotyczą zmian struktury organizacyjnej kręgu: tworzenia 


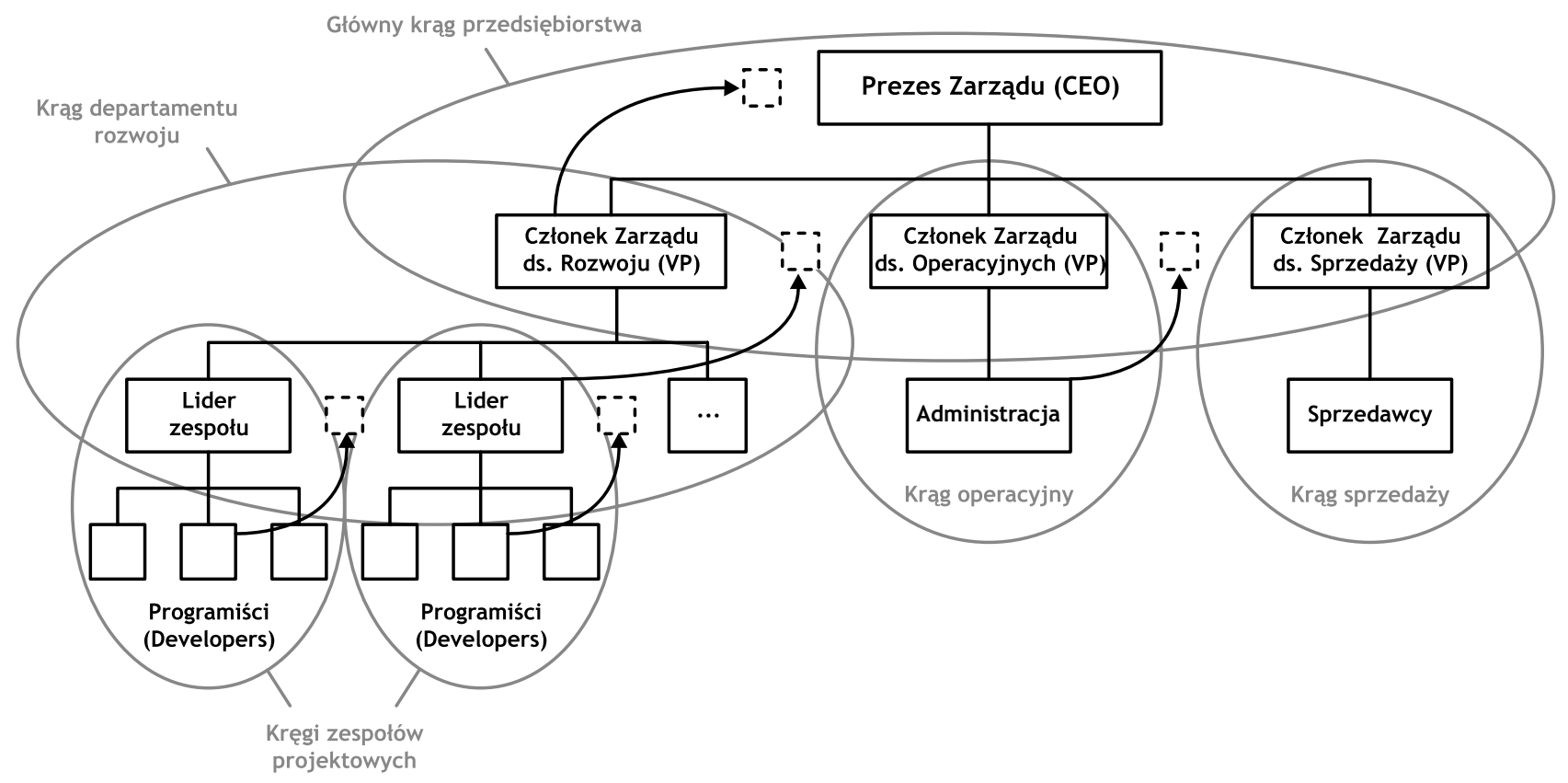

Rys. 1. Struktura przedsiębiorstwa holakratycznego

Źródto: opracowanie wtasne na podstawie: Robertson, 2006, s. 7

nowych lub modyfikacji dotychczasowych ról, reguł, przeprowadzania wyborów (przydzielania ról). Drugie związane są z rozwiązywaniem bieżących problemów w realizacji zadań (napięć). W rezultacie tych zebrań następuje wyznaczenie kolejnych celów oraz zadań. Prezentowane są także dotychczas osiągnięte wyniki (Konstytucja holakracji (wersja 4.1), 2017; Robertson, 2006; 2015; Chrapko, 2016).

Zebrania kręgów (szczególnie operacyjne) odbywają się często (co najmniej raz w tygodniu). Aby zapewnić wysoką efektywność tych spotkań, stosuje się ściśle określone zasady ich przebiegu. Dla każdego zebrania wyznacza się osobę „moderatora” (facylitatora), która jest specjalnie przeszkolona do pełnienia tej funkcji. Zadaniem facylitatora jest kierowanie przebiegiem zebrania według określonych zasad. W zebraniach uczestniczą wszyscy członkowie kręgu oraz osoby zaproszone $\mathrm{z}$ innych kręgów, jeśli wymaga tego specyfika rozpatrywanego problemu. $\mathrm{O}$ zebraniu powiadamia, $\mathrm{z}$ odpowiednim wyprzedzeniem, sekretarz kręgu.

Zebrania zarządcze realizowane są według stałego scenariusza, obejmującego cztery etapy: rundę otwierającą, kwestie administracyjne, budowanie agendy i rozpatrywanie problemów (napięć), rundę zamykającą. W ramach rundy otwierającej każdy $\mathrm{z}$ uczestników przedstawia problemy w zakresie wypełnianej przez siebie roli. Na tym etapie nie jest jeszcze podejmowana dyskusja. Etap drugi dotyczy kwestii administracyjnych lub logistycznych, które wymagają przedyskutowania. Zasadniczą część zebrania stanowi runda trzecia. W ramach tej rundy facylitator buduje, na podstawie wypowiedzi uczestników zebrania, agendę problemów i następnie każdy z nich jest rozpatrywany. Każdy punkt agendy reprezentuje jeden problem. Uczestnik zebrania może zgłosić dowolną liczbę problemów do rozpatrzenia. Na zebraniu rozpatrywane są tylko zgłoszone problemy. Kolejność rozpatrywania problemów określa facylitator. W sytuacji gdy jednak zebranie zostało zorganizowane na wniosek jednego z uczestników, zgłoszone przez niego sprawy rozpatrywane są w pierwszej kolejności. Podobnie gdy zgłoszony wniosek dotyczy zmiany roli. Sprawy rozpatrywane są osobno. Rozpatrzenie sprawy następuje $\mathrm{w}$ wyniku tzw. zintegrowanego procesu decyzyjnego lub zintegrowanego procesu wyborczego. Pierwszy z nich związany jest $\mathrm{z}$ rozpatrywaniem problemów dotyczących organizacji i funkcjonowania kręgu, drugi natomiast dotyczy wyboru osób do pełnienia określonych ról (rys. 2).

Zintegrowany proces decyzyjny realizowany jest według poniższych etapów: prezentacja propozycji, pytania wyjaśniające, runda reakcji, zmiany i wyjaśnienia, runda sprzeciwów, integracja. Proces decyzyjny rozpoczyna przedstawienie problemu przez osobę wnioskującą jego rozpatrzenie, która również proponuje wstępną propozycję jego rozwiązania. Propozycje takie mogą zgłosić także inni uczestnicy zebrania. Zadaniem facylitatatora na tym etapie jest czuwanie, aby istota problemu została w pełni przedstawiona oraz zgłoszone rozwiązania dotyczyły tylko tego problemu. Po tym etapie następuje runda zadawania pytań, której celem jest lepsze zrozumienie problemu. Pytania może zadawać każdy uczestnik zebrania. Facylitator musi natomiast uniemożliwić wszelkie reakcje lub opinie oraz zapobiec jakiejkolwiek dyskusji. Po wyczerpaniu wszystkich pytań następuje runda reakcji. Polega ona na wyrażeniu kolejno, przez każdego z uczestników zebrania, opinii na temat omawianego problemu. Facylitator nie dopuszcza do wypowiedzi poza kolejnością oraz dyskusji i sporów. Po rundzie reakcji zgłaszający problem może odnieść się do przedstawionych wypowiedzi i zaproponować zmianę propozycji rozwiązania problemu. Zmiana ta musi jednak wskazywać lepsze rozstrzygnięcie od wcześniej proponowanego, a nie stanowić formy 
dostosowania do oczekiwań osób zgłaszających uwagi. Kluczową rolę w tym względzie odgrywa facylitator. Każdy z uczestników zebrania może wnieść sprzeciw wobec przyjęcia przedstawionej propozycji (runda sprzeciwów). Zgłoszone sprzeciwy facylitator może poddać testowaniu. Polega ono na zadawaniu pytań wnoszącemu sprzeciw. Aby złożony sprzeciw pozytywnie przeszedł test, sprzeciwiający musi przedstawić racjonalne argumenty. Facylitator przyjmuje wówczas zgłoszony sprzeciw i powraca do dyskusji, aby wprowadzić zmiany w propozycji, uwzględniające przedstawione uwagi. Postępowanie to prowadzone jest do momentu braku dalszych, konstruktywnych sprzeciwów. Wypracowane w ten sposób rozstrzygnięcie stanowi rozwiązanie problemu. Procedura odbywa się w ramach ostatniego etapu zintegrowanego procesu decyzyjnego - integracji.

Zintegrowany proces wyborczy obejmuje natomiast następujące etapy: opis roli, wypełnienie kart do głosowania, rundę nominacji, rundę zmiany nominacji, przedstawienie propozycji, rozstrzygnięcie propozycji. Proces rozpoczyna podanie przez facylitatora istotnych informacji na temat roli, której dotyczą wybory. Następnie każdy z uczestników zebrania wpisuje na karcie imię jednego kandydata, który - jego zdaniem - najlepiej wypełni tę rolę. Nie można wskazać więcej niż jednej osoby. Karty podpisywane są również przez nominujących. W trakcie wypełniania kart uczestnicy zebrania nie mogą wyrażać opinii i podejmować dyskusji na temat kandydatów. Opinie dotyczące kandydatów przedstawiane są w kolejnej rundzie - nominacji. Facylitator podaje do wiadomości wszystkich, po kolei, treść każdego oddanego głosu, prosząc jednocześnie osobę dokonującą nominacji o uzasadnienie swojego wyboru. Opinie wyrażane są tylko przez autorów nominacji. Wszelkie uwagi i dyskusje pozostałych osób są wstrzymywane przez facylitatora. Następnie ma miejsce runda zmiany nominacji, w trakcie której każdy z głosujących ma prawo do zmiany swojej nominacji, przedstawiając powód. W dalszej kolejności facylitator zlicza głosy i występuje z propozycją wyboru kandydata $z$ największą liczbą nominacji. W sytuacji takiej samej liczby głosów u dwóch lub więcej kandydatów o ostatecznym wyborze może zadecydować facylitator.

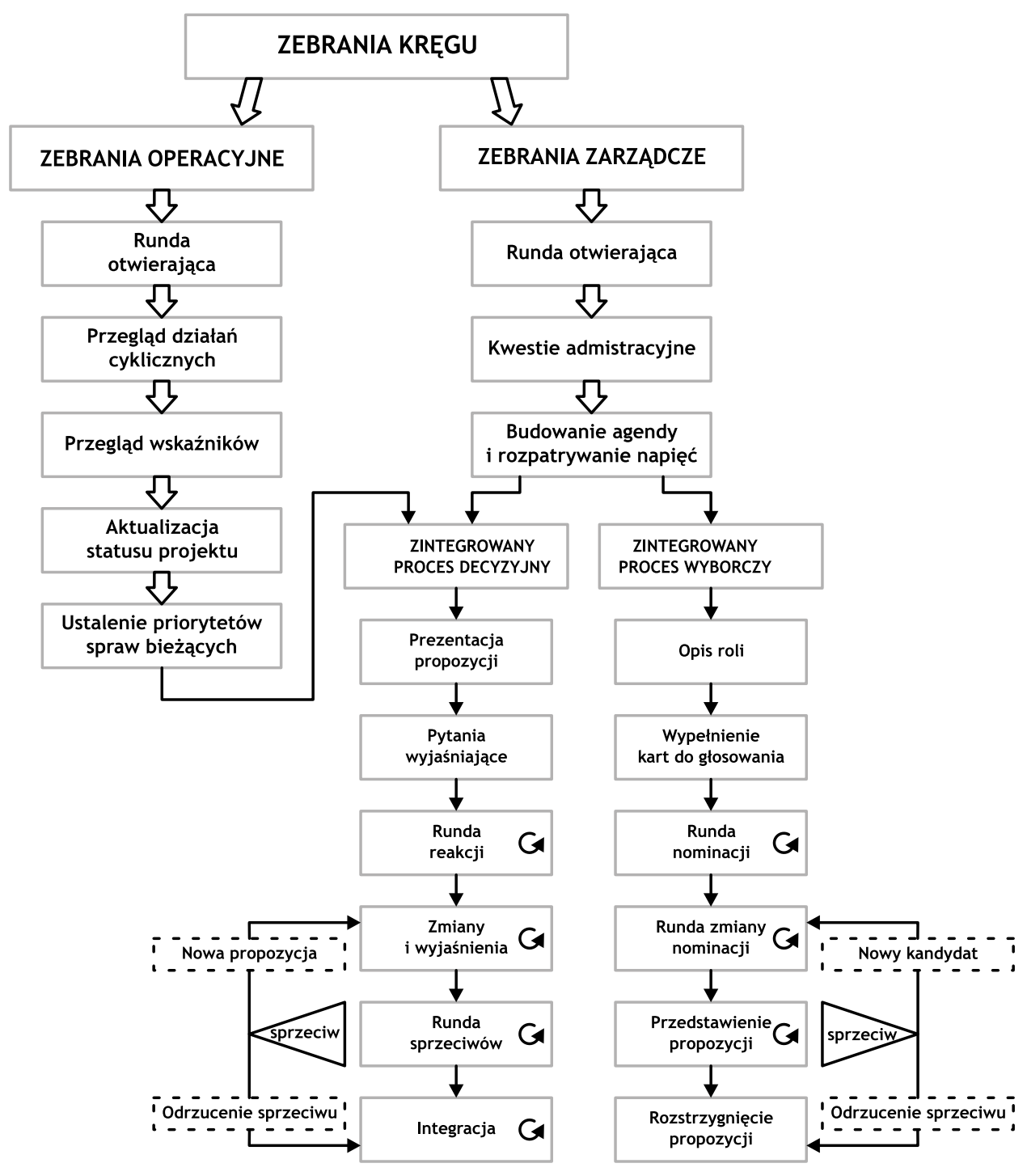

Rys. 2. Schemat organizacji zebrań kręgu

Źródło: opracowanie własne na podstawie: Konstytucja holakracji (wersja 4.1), 2017 
Każdy z uczestników zebrania może zgłosić sprzeciw do wyboru danej osoby. W sytuacji uzasadnionego sprzeciwu rozstrzygnięcie odbywa się na zasadach rundy integracji, w ramach zintegrowanego procesu decyzyjnego.

Celem zebrań operacyjnych natomiast jest:

- przedstawienie sprawozdania $\mathrm{z}$ realizacji bieżących zadań kręgu,

- omówienie wyników kręgu (mierników postępu),

- przedstawienie postępów w realizacji projektów kręgu,

- rozwiązanie problemów związanych $\mathrm{z}$ realizacją bieżących zadań oraz projektów i wyznaczenie kolejnych działań.

Odpowiedzialnym za planowanie zebrań operacyjnych jest sekretarz kręgu. W zebraniu tym uczestniczą, podobnie jak w przypadku zebrania zarządczego, wszyscy członkowie kręgu oraz zaproszone osoby z innych kręgów, jeśli wymaga tego specyfika rozpatrywanych problemów. Również w tym przypadku przebiegiem zebrania kieruje facylitator. Zorganizowane jest ono w układzie pięciu następujących etapów: runda otwierająca, przegląd działań cyklicznych, przegląd wyników (mierników wyników), aktualizacja statusu projektów, ustalenie priorytetów spraw bieżących.

Zebranie rozpoczyna się od podzielenia się przez uczestników aktualnymi przemyśleniami lub innego rodzaju uwagami na temat aktualnych problemów w realizacji zadań, wyłączając na tym etapie dyskusję. Następnie facylitator prosi każdego uczestnika o zweryfikowanie, czy wszystkie przypisane działania do uczestnika zostały zakończone. Uczestnicy przedstawiają również informacje na temat uzyskanych wyników. Podają wielkości mierników związane z ich aktywnością. W dalszej kolejności uczestnicy zebrania prezentują postęp, jaki uzyskali w realizacji zadań lub projektów od ostatniego zebrania. Następnie facylitator ustala agendę problemów bieżących do rozstrzygnięcia w trakcie zebrania. Rozwiązywanie wyznaczonych problemów przebiega według takiego samego schematu jak w przypadku zebrań zarządczych.

Ostatnią fazą zarówno zebrania zarządczego, jak i operacyjnego jest runda zamykająca. W jej trakcie facylitator zaprasza każdego uczestnika do podzielenia się końcową refleksją na temat spotkania i przyjętych ustaleń.

Przedstawione zasady organizacji zebrań kręgów zwiększają sprawność ich przebiegu oraz umożliwiają osiągnięcie konstruktywnych rozwiązań.

\section{Holakracja w praktyce}

W ogólnodostępnych źródłach można odnaleźć wiele informacji na temat organizacji, które osiągnęły sukces dzięki wdrożeniu holakracji. Najbardziej znanym przykładem jest firma Zappos. Firma ta swoją działalność rozpoczęła w 1999 roku. Została utworzona na bazie kapitału inwestycyjnego pozyskanego $\mathrm{z}$ funduszu Venture Fogs, w wysokości 1,1 mln dolarów. Firma od początku zajmowała się internetową sprzedażą odzieży i obuwia. Już w ciągu pierwszego roku działalności osiągnęła ogromy sukces rynkowy. Aby zapewnić dalszy dynamiczny jej rozwój, kierowanie Zapposem powierzono doświadczonemu menedżerowi Tony’emu Hsiehowi, który wcześniej pełnił funkcję dyrektora generalnego Venture Fogs. T. Hsieh wyznaczył dwa główne cele, które firma miała osiągnąć do 2010 roku: przychód w wysokości 1 mld dolarów oraz znaleźć się na liście rankingu Fortune „Najlepsza firma do pracy”. Sposobem osiągnięcia tych celów miało być stworzenie silnej kultury organizacyjnej, która będzie inspirowała i motywowała wszystkich pracowników do prawdziwego zaangażowania w rozwój firmy. Wizję tę udało się zrealizować T. Hsiehowi. Zappos osiągnął przychody na poziomie 1 mld dolarów już w 2008 roku, a na liście Fortune znalazł się rok później (Kopelman i in., 2012, s. 66).

T. Hsieh kontynuował rozwój firmy poprzez doskonalenie kultury organizacyjnej. W marcu 2015 roku wysłał do pracowników e-mail, w którym oświadczył, że wszyscy pracownicy będą mieli możliwość wypróbowania swoich kompetencji w zakresie samorządności. Tradycyjna hierarchia zostanie zastąpiona holakracją, która ma na celu zapewnianie wyższego poziomu kreatywności i innowacji (Thomas, Silverstone, 2015).

Firma określiła 10 głównych wartości swojej kultury: szczęście, ludzie, bycie sobą, wyjątkowość, zabawa, trwałe zasady, nie tylko mierzalne wyniki, integracja pracy i życia, dobre relacje $\mathrm{z}$ partnerami biznesowymi, rzeczywistość, podstawowe wartości, marka (zapposinsights.com). Wiele z nich wynikało z poznania czynników przyczyniających się do wydajności biznesu.

Firma Zappos przyjęła koncepcję holakracji przedstawionej przez B. Robertsona. Tradycyjne działy zostały zastąpione kręgami, a stanowiska rolami. Zlikwidowano stanowiska kierownicze. Wszystkie decyzje podejmowane są kolektywnie, w ramach zebrań kręgów. Wdrożenie holakracji w Zappos przyczyniło się do sukcesu firmy. Należy jednak zwrócić uwagę, że zmiana ta wiązała się także z pewnymi problemami. Sama informacja o wprowadzaniu holakracji spowodowała odejście z pracy $18 \%$ pracowników. Przyczyną ich decyzji było przekonanie, że nie będą w stanie skutecznie działać w nowych warunkach. Obserwowaną negatywną konsekwencją holakracji był również wzrost biurokracji. Firma ciągle rozwija swój system, doskonaląc różne jego aspekty. Problemem, który w ostatnim czasie firma starała się rozwiązać, była kwestia powiązania wynagrodzenia $\mathrm{z}$ rolami pełnionymi przez pracowników (Sunny, 2014).

Poprawę efektywności działania dzięki wdrożeniu holakracji osiągnęło również wiele innych przedsiębiorstw. Jako przykłady można podać: Davitę - firmę sprzedająca sprzęt medyczny, firmy informatyczne Menlo Innovations i Valve Software czy Precision Nutrition, zajmującą się treningiem personalnym (Krasulja i in., 2016, s. 194).

Nie wszystkim jednak udało się odnieść sukces związany z holakracją. W źródłach literaturowych można odnaleźć również informacje na temat firm, które po kilku latach stosowania holakracji zaprzestały jej. Przykładem może być firma Medium, będąca platformą publikacyjną, która po trzech latach stosowania tej koncepcji zrezygnowała $\mathrm{z}$ niej (Timmerman, 2016). Zdaniem prezesa firmy Evana Williamsa, koncepcja ta nie do końca pasuje do 
specyfiki takich przedsiębiorstw jak Medium. Działalność tej firmy polega głównie na realizacji dużych projektów, wymagających współpracy wielu kręgów. W tych warunkach, zdaniem E.Williamsa, brak silnego przywództwa się nie sprawdza. W rezultacie w firmie miało miejsce znaczne zwiększenie biurokracji oraz konflikty. Jak podkreśla E. Williams, odejście od holakracji w Medium nie oznacza wcale powrotu do dawnego modelu zarządzania. Wiele aspektów holakracji, jak: kolektywne podejście, otwartość komunikacyjna, zmienność ról, to osiągnięcia, które będą w firmie kontynuowane (Battelle, 2016).

\section{Próba oceny koncepcji}

$\mathbf{H}$ olakracja jest koncepcją mającą zarówno zwolenników, jak i przeciwników. Przykłady jej zastosowania w praktyce wskazują na liczne potencjalne korzyści, jakie mogą wynikać z wdrożenia tego podejścia, jak również zagrożenia i problemy (tab. 1). Niewątpliwie jedną z najważniejszych korzyści holakracji jest zwiększenie elastyczności organizacji oraz motywacji i zaangażowania pracowników. Korzyści te związane są ze spłaszczeniem struktury organizacyjnej i przekazaniem odpowiedzialności za wyniki oraz rozwój firmy zespołom pracowniczym (kręgom). Realny wpływ pracowników na funkcjonowanie organizacji, związany z kolektywnym podejmowaniem decyzji, przyczynia się do wzrostu identyfikacji z firmą i zaangażowania pracowników. Powoduje również rozwój indywidulanych kompetencji i kreatywności pracowników. Czynniki te przekładają się na wyższą sprawność decyzyjną oraz wpływają pozytywnie na ogólną efektywność organizacji.

Tabela 1. Potencjalne korzyści oraz ograniczenia holakracji

\begin{tabular}{|c|c|}
\hline Korzyści & Ograniczenia i zagrożenia \\
\hline $\begin{array}{l}\text { - } \text { elastyczność organizacji } \\
\text { - } \text { rozwój kompetencji } \\
\text { - empowerment } \\
\text { - wysokie zaangażowanie } \\
\text { i motywacja } \\
\text { - poczucie wspólnoty } \\
\text { - kreatywność pracowników } \\
\text { - szybkie decyzje } \\
\text { - otwartość informacyjna } \\
\text { - podejście procesowe } \\
\text { - orientacja na wyniki } \\
\text { - efektywność }\end{array}$ & $\begin{array}{l}\text { - } \text { biurokracja } \\
\text { - rozmyta odpowiedzialność } \\
\text { - niestabilność } \\
\text { - trudność w utrzymaniu } \\
\text { spójnej wizji rozwoju } \\
\text { - wielość ról i rozdrobnienie } \\
\text { pracy } \\
\text { - nieadekwatność } \\
\text { wynagrodzenia do wartości } \\
\text { pracy }\end{array}$ \\
\hline
\end{tabular}

Źródto: opracowanie własne

Przeciwnicy holakracji jako główne zagrożenie tej koncepcji wskazują wzrost biurokracji, wynikający z formalizacji procesu zarządzania. Najczęściej powodowana jest ona ścisłym stosowaniem się w działaniu do regulaminu organizacyjnego, opracowanego na podstawie konstytucji holakracji. Potencjalnym zagrożeniem jest również rozmyta odpowiedzialność, wynikająca z braku leadera (kierownika) oraz wielości i rozdrobnienia ról. W takich warunkach koordynacja działań i doprowadzenie do określonych, wspólnych wyników staje się niezwykle trudnym zadaniem. Okazuje się często, że zastosowanie "podwójnego łączenia” pomiędzy kręgami jest niewystarczające. Sytuacja taka miała miejsce w firmie Medium. Realizując duże projekty, angażujące wiele kręgów, brak „silnego” leadera, koordynującego całe przedsięwzięcie, okazał się główną przyczyną niepowodzenia (Timmerman, 2016). Należy również mieć na uwadze, że nie wszystkim pracownikom odpowiada model zarządzania „bez szefa”. Nie wszyscy chcą przyjmować odpowiedzialność za firmę w tak dużym zakresie, jak oczekiwane jest to $\mathrm{w}$ holakracji. Posiadanie przełożonego, dla wielu osób jest wygodnym rozwiązaniem. Szczególnie tego typu postawy obserwowane są wśród pracowników o niższym poziomie kompetencji (przygotowania zawodowego). Dlatego koncepcja ta nie we wszystkich warunkach może okazać się skuteczna. Najbardziej właściwym środowiskiem dla jej wdrażania wydają się młode organizacje, działające $\mathrm{w}$ formule projektowej, zatrudniające wysoko kwalifikowany personel, zorientowane na szybki wzrost. Charakterystyce tej w szczególności odpowiadają startupy. Niestabilność organizacyjna przekłada się również na trudności w zakresie motywowania pracowników, w tym ich właściwego wynagradzania. Tradycyjne systemy, polegające na wiązaniu wynagrodzenia $\mathrm{z}$ trudnością zadań realizowanych przez pracownika, w ramach przypisanego zakresu obowiązków, nie sprawdzają się w tych warunkach. Kluczową determinantą wynagrodzenia stają się kompetencje pracowników i ich potencjał z perspektywy organizacji. Konieczne jest również wykorzystywanie różnych form premiowania wynikowego. Bardzo skutecznym rozwiązaniem motywacyjnym, które powoduje wysokie zaangażowanie oraz identyfikację z firmą, jest stosowanie wynagrodzenia odroczonego w czasie, głównie w formie nabywania przez pracowników praw związanych $\mathrm{z}$ udziałem we własności firmy (opcje, akcje).

\section{Podsumowanie}

$\mathrm{H}$ olakracja to młoda koncepcja zarządzania. Znajduje się ona nadal w fazie rozwoju. Wiele szczegółowych problemów, związanych $\mathrm{z}$ jej funkcjonowaniem, wymaga rozwiązania. Niezależnie od tego należy uznać, że ogólne jej założenia wpisują się we współczesne trendy ewolucyjne zarządzania, związane z: rosnącą rolą zasobów ludzkich, decentralizacją zarządzania, konicznością zapewnienia elastyczności w działaniu, partycypacją, uczeniem się organizacyjnym. Tendencje te nabierają szczególnego znaczenia w warunkach pokoleń Y i Z. Przedstawiciele tych generacji to $\mathrm{z}$ reguły pracownicy dobrze wykształceni, posiadający szerokie kompetencje, mobilni zawodowo oraz życiowo. Osoby te nie chcą występować tylko w roli podporządkowanych wykonawców. Możliwość samorealizacji, wpływu na organizację, zaspokojenie poczucia wysokiej własnej wartości jest dla nich niezwykle ważne. Dlatego należy się spodziewać, że holakracja, jak również inne koncepcje zarządzania, oparte na samoorganizacji, będą znajdowały coraz szersze zastosowanie w praktyce gospodarczej, tworząc realną alternatywę dla „tradycyjnego” modelu zarządzania. 
Przedstawiona w artykule problematyka wymaga dalszych badań naukowych, przede wszystkim empirycznych. Badania te powinny dotyczyć takich aspektów, jak: zmienność ról powierzanych pracownikom, współpraca wewnątrzorganizacyjna (pomiędzy kręgami), integracja organizacyjna, odpowiedzialność realizacyjna, komunikowanie zespołowe, motywowanie pracowników. Kluczowym problemem badawczym w tym względzie jest jednak ocena skuteczności zastąpienia tradycyjnego podejścia do zarządzania holakracją. Badania związane $\mathrm{z}$ tym problemem mogą polegać na porównaniu skuteczności zarządzania $\mathrm{w}$ przedsiębiorstwach tego samego rodzaju, stosujących tradycyjne podejście do zarządzania oraz holakrację.

\section{dr hab. Bernard Ziębicki, prof. uczelni Uniwersytet Ekonomiczny w Krakowie Kolegium Nauk o Zarządzaniu i Jakości ORCID: 0000-0003-3628-8264 \\ e-mail: ziebicki@uek.krakow.pl}

\section{Bibliografia}

[1] Battelle J. (2016), Understanding Medium: Evan Williams On His Past, Future, and Current Obsessions, „Newco Shift”, https://shift.newco.co/2016/08/09/understanding-medium -evan-williams-on-his-past-future-and-current-obsessions/, access date: 20.06.2019.

[2] Bhandari R., Colomo-Palacios R. (2019), Holacracy in Software Development Teams: A Multivocal Literature Review, Proceedings of 19th International Conference on Computational Science and its Applications, Saint Petersburg, Russia, July, 1-4, pp. 140-145.

[3] Buck J., Villines S. (2007), We the People: Consenting to a Deeper Democracy. Sociocracy.info, Washington D.C.

[4] Chrapko M. (2016), Holakracja - nowy sposób na zwinna firme, http: mariuszchrapko.com/holokracja-czyli-nowy-sposob-na-zwinna-firme/, data dostępu: 20.04.2019 r.

[5] Cobb Ch.G. (2012), Zrozumieć Agile Project Management. Równowaga kontroli i elastyczności, APN Promise, Warszawa.

[6] Eckstein J., Buck J. (2018), Company-wide Agility with Beyond Budgeting, Open Space \& Sociocracy: Survive Thrive on Descruption, CreateSpace Independent Publishing Platform, US.

[7] Gulati R. (2018), Structure that's not Stifling, „Harvard Business Review", No. 96(3), pp. 68-79.

[8] Koestler A. (1967), The Ghost in the Machine, Hutchinson, London.

[9] Konstytucja holakracji (wersja 4.1) (2017), https://www. dwarfsandgiants.org/wp-content/uploads/dG_Holacracy_Konstytucja_Holakrcji_v4_A4_PL.pdf, data dostępu: 20.07.2019 r.

[10] Kopelman R.E.; Chiou A.Y., Lipani L.J., Zhu Z. (2012), Interpreting the Success of Zappos.com, Four Seasons, and Nordstrom: Customer Centricity is but One-Third of the Job, „Global Business and Organizational Excellence: A Review of Research \& Best Practices", Vol. 31, No. 5, pp. 63-77.
[11] Krasulja N., Radojević I., Janjušić D. (2016), Holacracy - New Management System, [in:] The Priority Directions of National Economy Development, Conference Paper, Faculty of Economics, University of Niš, pp. 187-196.

[12] Laloux F. (2015), Pracować inaczej, Wydawnictwo Studio EMKA, Warszawa.

[13] Robertson B. (2006), Holacracy: A Complete System for Agile Organizational Governance and Steering, „Project Management", Vol. 7, No. 7, pp. 1-23.

[14] Robertson B. (2015), Holacracy: The New Management System for a Rapidly Changing World, Henry Holt and Company LLC, New York.

[15] Romme G. (1995), The Sociocratic Model of Organizing, "Journal of Strategic Change", Vol. 4, No. 4, pp. 209-215.

[16] Sunny A. (2014), Zappos Holacracy. People's Lab blog, MSL Group, http://peopleslab.mslgroup.com/peoplesinsights/ zappos-holacracy/, access date: 20.05.2019.

[17] Thomas R.J., Silverstone Y. (2015), Empowering Employees at Zappos, https://www.accenture.com/t20151015T042910 __w__/us-en/_acnmedia/Accenture/Conversion-Assets/ Outlook/Documents/2/Accenture-Outlook-ZapposWeb-PDF.pdf, access date: 20.05.2019.

[18] Timmerman R. (2016), Medium Drops Holacracy: How We Dealt with Their Challenges at Springest in the Past 3 Years, https://medium.com/@rubzie/medium-drops-holacracy-how-we-deal-with-their-problems-after-3-years-12428b373b5f, access date: 20.06.2019.

[19] Van de Kamp P. (2014), Holacracy - A Radical Approach to Organizational Design, [in:] Elements of the Software Development Process - Influences on Project Success and Failure, Editors: Hans Dekkers, Wil Leeuwis, Ivan Plantevin, University of Amsterdam, pp. 13-25.

[20] Wilber K. (2001), A Brief History of Everything, Shambhala, Boston.

[21] www.zapposinsights.com/r/culture-is, access date: 20.06.2019.

\section{Holacracy as a New Concept of Flexible Organisation - An Attempt of Assessment}

\section{Summary}

The article is focused on the holacracy, which is one of the new concepts of self-organisation. The holacracy has not been widely described in the scientific literature and the subject is usually treated from the practical perspective. The article presents the genesis and essence of holacracy. The organisational structure and the principles of its operation are characterised in it. The decision-making process within the circle meetings is discussed in detail. Selected examples of applying holacracy in business practice are presented. The author identifies in the article potential advantages and disadvantages of holacracy. The main advantages of holacracy include: increased organisation flexibility, development of an individual employee's competences, empowerment, increased commitment and motivation, higher sense of community among employees, creativity, quick decisions, information openness, process-based approach and orientation on results. The risks 
connected with holacracy implementation are as follows: bureaucracy, fuzzy responsibility, instability, difficulty in maintaining a consistent vision of development, multiple roles and fragmentation of work, inadequacy of remuneration for the value of work. Directions of further research in this area are also indicated and should concern such aspects as: variability of roles entrusted with employees, intra-organisational cooperation (between circles), organisational integration, implementation responsibility, team communication, employee motivation. However, the key research problem in this area is to assess the efficiency of the replacement of the traditional management methods with holacracy.

\section{Keywords}

holacracy, self-organization, agile management, sociocracy, flexible organisation 